\title{
A comparative study on different physicochemical properties of fresh and frozen lamb meat
}

\author{
A. K. M. Sarwar Inam ${ }^{1}$, R. Ahmmed ${ }^{2}$ and M. A. Haque ${ }^{3}$ \\ ${ }^{1}$ Department of Nutrition and Food Engineering, Daffodil International University, Dhaka \\ ${ }^{2}$ Department of Food Technology and Engineering, Patuakhali Science and Technology University, Patuakhali. \\ ${ }^{3}$ Department of Food Technology and Nutritional Science, Mawlana Bhashani Science and Technology University, Tangail.
}

\section{ARTICLE INFO}

Article history:

Received: 14 September 2017

Accepted: 21 October 2017

Keywords:

Lamb meat, Frozen lamb, Fresh lamb,

Physicochemical, Meat texture

Correspondence:

(inam.nfe@diu.edu.bd )
A.K.M. Sarwar Inam

\begin{abstract}
This study described the comparison of different physicochemical parameters between fresh and frozen lamb meat. The $\mathrm{pH}$ measurement for fresh and frozen lamb meat did not show a significant difference. CIE L*a*b* (Commission Internationale de l'éclairage) color measurement technique was used and $\Delta \mathrm{E}$ (distance between 2 colors) was found 5.32. On shrinkage measurement, there were significant differences $(\mathrm{p}<0.05)$ between the fresh and frozen meat. Frozen lamb sample showed $26.99 \%$ shrinkage compared to the fresh lamb which showed $18.09 \%$ shrinkage. The thawing loss did not show any significant difference. For texture analysis force and work were evaluated together for both fresh and frozen samples through Warner Bratzler texture analysis. The values did not show any significant difference. The absolute values of force and work were significantly different $(\mathrm{p}<0.05)$. Water binding capacity of the frozen and fresh sample were $56.57 \%$ and $59.27 \%$, respectively. The moisture contents of fresh and frozen sample were $73.64 \%$ and $72.85 \%$, respectively. Fat contents of fresh and frozen sample were $5.08 \%$ and $6.09 \%$ respectively. The study concludes that while comparing fresh and frozen lamb, only shrinkage and texture analysis showed significant difference whereas other physicochemical properties showed minor differences.
\end{abstract}

\section{Introduction}

From the last decade, a progressive declination was occurred for the global sheep industry for many possible reasons such as seasonal drought, unpredictable weather patterns, decreasing land resource and an unsteady economic condition with fluctuating meat prices. Dickson-Hoyle and Reenberg (2009) reported that not only the price of lamb meat but also the quality greatly affects the consumption of lamb meat and meat products. Lamb meat quality is assessed by several factors such as color, tenderness, juiciness, fat content, water binding capacity etc. The importance of these factors depends on how the consumer uses the meat (Spooncer, 1979). All these properties may show variation in the result when compared with fresh and frozen meat. Changes occur in the qualities when meat sample goes under freezing and thawing (Singh and Wang, 1977). When water inside the meat goes under the frozen condition the concentration of the solute (proteins, carbohydrates, lipids, vitamins, and minerals) inside the meat muscle increases and that disturbs the homeostatic properties of the complex meat system (Lawrie, 1998). This change greatly influences the cell membrane characteristics of muscle fiber which directly affect the meat quality (Leygonie et al., 2012). The changes in the quality are important to assess the lamb meat for the food industries as their main objective is to reduce or minimize any effect which occurs during freezing (Renerre, 1990).
Because of the expanding of global trade and the extending the distance between producer and consumer, meat freezing for storage and transportation is of great importance. The objective of this study is to determine any significant difference between fresh and frozen lamb meat in case of $\mathrm{pH}$, color, shrinkage, weight loss, thawing loss, texture, water binding capacity, moisture and fat content. The possible reasons for significant differences and the ways to reduce those changes and some recommendations are also discussed in this study.

\section{Materials and Methods}

Preparation of meat samples: Total $12 \mathrm{~kg}$ of lamb meat (Portion: hind-shank) was purchased from a meat processing company. At first, $6 \mathrm{~kg}$ of lamb meat was taken for analysis which was regarded as a fresh sample. Fresh samples took 14 days of the period to go for different analysis and for this reason, another $6 \mathrm{~kg}$ of lamb meat was kept below $-18^{\circ} \mathrm{C}$ for this period of two weeks and was regarded as a frozen sample. Both samples were cut and processed in the laboratory of the Department of Food Technology, Anhalt University of Applied Sciences, Germany. The samples were made fat free, deboned and portioned. Each portion weighted around $1 \mathrm{Kg}$. Before and after the deboning process both fresh and frozen meat were stored separately in the cooling chamber at $3.5^{\circ} \mathrm{C}$ for experiments. 
pH measurement: Determination of $\mathrm{pH}$ value in case of meat processing has a special importance as it directly influences shelf-life, color, and quality of meat (Fernandes-Lopez et al. 2005). To measure $\mathrm{pH}$ with WTW handheld pH meter (Xylem Analytics Germany Sales $\mathrm{GmbH} \& \mathrm{Co}$. KG), 5 fresh and 5 frozen samples were selected randomly. The value of $\mathrm{pH}$ meter is always temperature dependent, therefore, the temperature of all the samples was maintained $3^{\circ} \mathrm{C}$ to avoid any error in the calculation. The $\mathrm{pH}$ was determined by penetrating the electrode to the muscle directly. The electrode of the handheld $\mathrm{pH}$ meter was cleaned after each measurement. Each measurement was recorded carefully.

CIELab color measurement: Lange Spectro Color Portable Spectrophotometer (Hach Lange Ltd.) (Measuring aperture: $10 \mathrm{~mm}$ illuminated/ $8 \mathrm{~mm}$ measured, Illuminants: CIE D65, C, A, F 11, TL 84) was used for color measurement. Randomly selected fresh samples and frozen samples were taken for measurement. L, a and b values were determined for each sample at $3^{\circ} \mathrm{C}$. The CIELAB system uses three coordinates to locate a color. Here L defines lightness, "a" defines the red/green value and "b" denotes yellow/blue value (CIELAB, 2014). Delta E value was measured also to get the difference between the colors of fresh and frozen samples. Delta $\mathrm{E}$ is an examination to evaluate the color difference from a known standard. The expression of these color differences is denoted by $\Delta \mathrm{L}, \Delta \mathrm{a}$ and $\Delta \mathrm{b}$ (here $\Delta$ or Delta indicates differences). The total differences of two CIELAB value can be denoted by one numerical value that is known as $\Delta \mathrm{E}$. If the $\Delta \mathrm{E}$ values go more than 1 , there will be a significant difference, as the value 1 denotes Just Noticeable Difference (JND). The formula is as follows.

$$
\Delta E=\sqrt{\left(\Delta L^{2}+\Delta a^{2}+\Delta b^{2}\right)}
$$

Weight loss and shrinkage measurement: Randomly selected samples of fresh and frozen lamb meat were arranged by the desired dimension such as length $4 \mathrm{~cm}$, height $2 \mathrm{~cm}$, and width $2 \mathrm{~cm}$ with the help of knife and ruler. The weight of each sample was measured at first and then cook in a microwave oven for 40 seconds. Samsung microwave oven of 1500 watt was used. Just after cooking each sample was measured again for weight to get the weight loss. The weight loss percentage of each sample was determined. Only the length of each sample was measured for shrinkage analysis using a slide caliper. Sometimes it was measured two times and the average value was taken. Average values and standard deviation were done for fresh and frozen samples.

Thawing loss measurement: From the experiment of Rahman et al. (2015), it has been evaluated that thawing loss is closely related to protein oxidation and denaturation which are also responsible for $\mathrm{pH}$ declination and toughness. Fresh and frozen meat were selected randomly for thawing loss measurement. The selected samples were weighed to nearly $100 \mathrm{~g}$ to reduce the effect of sample size in the experiment. Thawing was done at room temperature for 6 hours. After thawing the final weight was measured again for each sample to find out the total loss in percentage.

Texture analysis measurement: Samples from fresh and frozen lamb meat were taken randomly for texture analysis. Warner Bratzler Texture Analyser from Stable Microsystem was used for this measurement. The temperature of the meat sample should be chilling temperature to avoid the instrumental error. All the samples were measured at $4^{\circ} \mathrm{C}$ and length, height and width of each sample were $3 \mathrm{~cm} \times 2 \mathrm{~cm} \times 2 \mathrm{~cm}$. The test speed of the texture analyzer was $20 \mathrm{~mm} / \mathrm{sec}$. WarnerBratzler shear blade with "V" shape probe (cutting distance was $42 \mathrm{~mm}$ ) was used for raw meat and Warner-Bratzler shear blade with guillotine probe (cutting distance was $25 \mathrm{~mm}$ ) was used for fried meat. Sample area, force, and work were measured for each sample of fresh and frozen lamb meat using the following equations.

Sample area $\left(\mathrm{cm}^{2}\right)=\frac{h^{2}}{\sqrt{3}}$

Here, $\mathrm{h}=$ sample height $(\mathrm{cm})$

force $\left(N / \mathrm{cm}^{2}\right)=\frac{F}{s}$

Here, $\mathrm{F}=$ value for maximum force $(\mathrm{N})$ $\mathrm{s}=$ sample area $\left(\mathrm{cm}^{2}\right)$

work $\left(\mathrm{Ncm} / \mathrm{cm}^{2}\right)=\frac{A}{s}$

Here, $\mathrm{A}=$ value for work/area (N.cm) $\mathrm{s}=$ sample area $\left(\mathrm{cm}^{2}\right)$

Water binding capacity: Four fresh and frozen meat samples were taken for water binding capacity measurement. The weight of each sample was approximately $0.5 \mathrm{~g}$. Grau and Hamm (1953) filter paper press method was used to measure water binding capacity. A small amount of meat sample which was placed between two glass plates within filter paper was pressed by $1 \mathrm{~kg}$ weight for 10 minutes. For this force, water was squeezed out and the filter paper absorbed the water and a ring was formed. There will be two areas. The ring area was considered as outer area (b) and the meat area was considered as inner area (a). The area was measured with a planimeter. The following equation was used to find out the loose water.

Loose water $(\%)=\frac{b-a}{m} . F .100$

Here, $\mathrm{a}=$ area of meat, $\mathrm{cm}^{2}$

$\mathrm{b}=$ area of juice, $\mathrm{cm}^{2}$

$\mathrm{m}=$ sample weight, $\mathrm{g}$

$\mathrm{F}=$ factor for absorbency capacity of paper = $0.0084 \mathrm{~g} / \mathrm{cm}^{2}$ 
The water content was determined by oven dry method. Three samples of fresh meat and three samples were taken to measure moisture content. Each sample was $3 \mathrm{~g}$. In oven, dry method temperature was $105^{\circ} \mathrm{C}$ for 4 hours. The following equation was used to calculate water content.

Water content $(\%)=\frac{a-b}{a} \times 100$

Here, $a=$ sample weight before drying $(g)$

$\mathrm{b}=$ sample weight after drying $(\mathrm{g})$

From the three measurements of water content of both fresh and frozen meat, the average value was taken and put into the following equation.

Water binding capacity $(\%)=$ water content $(\%)$-loose water $(\%)$

Fat content: The Soxhlet extraction method was used for fat determination (Meat Update, 2014). Four thimbles were used; two for fresh lamb meat and two for frozen lamb meat.

Data analysis: The average values with a standard deviation of all the samples were calculated. Multiple comparisons test (Tukey's HSD) was done to check the significant differences $(\mathrm{p}<0.05)$ between fresh and frozen meat samples with the help of IBM SPSS Statistics software (Gomez and Gomez, 1984). The mean difference was significant at the level 0.05.

\section{Results and Discussion}

pH measurement: In the statistical comparison between fresh and frozen samples $\mathrm{pH}$, there was no significant difference in meat $\mathrm{pH}$ (Fig. 1). While freezing the sample, the fluid loss occurred in meat tissue could increase the concentration of the solutes which lower the $\mathrm{pH}$ value. A further explanation can be pointed out here. Microbial or enzymatic action cause deamination of proteins which releases hydrogen atoms and thus it lowers the $\mathrm{pH}$ value (Leygonie et al., 2011). As the meat sample was kept for freezing for only two weeks, the difference in $\mathrm{pH}$ value was not significant.

CIE Lab color measurement: The CIELAB color measurement has been done for both fresh and frozen samples (Fig. 2). As there was no significant difference found, Delta $\mathrm{E}$ has been determined to find out the difference between two samples. $\Delta \mathrm{E}$ was found 5.32 which is more than 1. Here 1 is the JND (Just noticeable difference). In a recent study, Mahy et al. (1994) assessed a JND 2.3 and the result was also more than 1, so it can be easily said that there was the difference in term of color in fresh and frozen samples. In the result, it was found that there were no noticeable color changes in fresh and frozen samples. Myoglobin is the component which is responsible for this color change in frozen meat (Anon and Cavelo, 1980). The denaturation of globin moiety occurs in the myoglobin molecule while freezing. This denaturation cause autoxidation of myoglobin which is the reason for color changing (Abdallah et al., 1999). In fresh meat the enzyme is in the active state, so the metmyoglobin which is formed earlier will be reduced to form deoxymyoglobin and it can also be oxygenated back to oxymyoglobin. Then the color of the meat will be pleasant. This activity was described by Livingston and Brown (1981) and termed as Metmyoglobin Reducing Activity (MRA). When the meat is in a frozen condition for too many days, the activity of the MRA falls down and the metmyoglobin aggregates all over the surface of the meat quickly. As the samples were kept in a full vacuum package, there was a little or no chance for the samples to come in contact with the oxygen of the air. These are the possible reasons for good color retaining.

Shrinkage and weight loss measurement: The average value of shrinkage loss was significantly higher in frozen than fresh sample (Fig. 3). The level of significance was $0.05 \%$. While freezing protein denatured and released water which caused this longitudinal shrinkage. Sometimes the meat piece of frozen sample was burst out while cooking. When the meat is not frozen in a quick freezer, there is a chance to accumulate water droplets together. These water droplets become a big drop of water and a big ice crystal is formed. On heating, this large ice crystal just becomes vaporized and the shrinkage occurs. That is the explanation of bursting out of frozen sample. The secondary standard deviation is also done because of the high value of standard deviation in both weight loss and shrinkage measurement.

For a fresh sample, the average value of weight loss was $36.99 \%$ and for a frozen sample, it was $40.41 \%$ (Fig. 4). And there was no significant difference when the level of significance was $0.05 \%$. Water inside the muscle fiber goes to vapor form while cooking and finally, it was fully vaporized. This is the possible reason for weight loss. But for a frozen sample, this water loss was more. Earle and Fleming (1967) and Fleming and Earle (1968) showed the evaporation of water from the surface of lamb meat during freezing in their research. This may be the possible reason for more weight loss in frozen samples.

When the temperature reaches $75^{\circ} \mathrm{C}$ at the time of heating, meat protein started to denature. Longitudinal and transversal shrinkage of muscle fiber and connective tissue shrinkage also take place at that time. Palka and Daun (1999) observed that while cooking in the range of temperature 45 to $90^{\circ} \mathrm{C}$, shrinkage can occur in two ways. At 45 to $60^{\circ} \mathrm{C}$ range, the shrinkage occurs as primarily transverse to the fiber axis of meat and at 60 to 
$90^{\circ} \mathrm{C}$ range, the shrinkage is primarily parallel type. It is known that when the temperature is more than $121^{\circ} \mathrm{C}$, the shrinkage will be then again transversal to the fiber axis. The same phenomenon was observed in this experiment.

Myofibrils in the muscle tissue contain most of the water. When any change of this water occurs, it affects the whole structure of muscle tissue. While cooking the structural changes happen and thus water holding capacity is reduced. In the time of cooking the shrinking connective tissue gives pressure to the water to expel. The term shrinkage is often used or referred as weight loss. It is used as an expression of water binding capacity (Newsome et al., 1985). Sometimes it is measured as a reduction in sarcomere length or fiber diameter (Tornberg, 2005). There may be another explanation of shrinkage that is cytoskeletal protein denaturation. At higher temperature, it causes shrinkage by pressing the myofibrillar components (Obuz et al., 2004)

Thawing loss measurement: Samples of fresh and frozen lamb meat were taken to measure the thawing loss. After 6 hours thawing the weight losses were measured (Fig. 5). The average values and standard deviation of fresh and frozen samples were calculated. Generally, the average value of weight loss percentage of frozen meat should be higher. But in the result, it has been seen that the fresh lamb sample showed the greater value of weight loss percentage. There were no significant interactive effects found on thaw loss in different fresh and a frozen sample which was similar to the experiments done by Rahman et al. (2014). The possible explanation of the greater value for fresh samples is that the fresh samples were not properly fresh and those were also kept in the frozen condition before the experiments. The thawing loss of meat depends on the thickness and the way the meat is cut. In this experiment ambient thawing was done which is actually not recommended by the food codes and regulation because of the risk of microbial spoilage (Met et al., 2013).

Texture analysis: Work and force were calculated to find out the texture. There was no significant difference found both for work and force. However, the standard deviation was high which indicated that the data were much scattered (Fig. 6). Hence, another calculation was done. Each value was deducted from the mean value and the average values were calculated from the final values. The standard deviation was also done again. This was done for both force and work of fresh and frozen samples. Multiple comparisons showed a significant difference in both samples. The level of significance was $0.05 \%$.

The average values of force showed that less force was needed for frozen samples (Fig. 7). From the calculation, it was observed that less work was done for frozen samples. Enzymatic reaction during proteolysis, the aging process and the loss of structural integrity by ice crystal formation were the explanations for this. When the meat is in a normal freezer, there is a chance to grow large, extracellular ice crystals. These ice crystals break the myofibrils apart and make the meat tender. Vieira et al. (2009) reported that small intracellular ice crystal can release the protease enzyme which causes proteolysis and tenders the meat. The reduced value in Warner Bratzler Texture Analyzer for frozen meat was due to the less strength of membrane because of ice crystal formation. This formation of ice crystal reduced the force which was applied to shear the meat (Lui et al., 2010).

This now becomes a general agreement that freezing and thawing make the meat tender when measured with peak force (Lagerstedt, Enfalt, Johansson, and Lundstrom, 2008). It has also been reported that this tenderness is directly related to the length of frozen storage and the degree of aging (Vieira et al., 2009).

Water binding capacity: To determine the water holding capacity, water content needed to measure at first. There is a little change in water content between fresh and frozen meat samples, i.e., $73.64 \%$ and $72.85 \%$, respectively (Fig. 8). The less difference indicated that the meat was frozen perfectly. However, water content of frozen lamb meat was a bit lesser than the fresh one. There some factors which are directly responsible for water loss while freezing meat. The factors are a reduction in $\mathrm{pH}$, the loss of ATP (Adenosine triphosphate) and the stearic effect for shrinkage. Previously water is bound to the protein in the intrafibrillar spaces and remains in an immobilized condition. These factors release water from that condition. The released water changes its position and accumulates to the sarcoplasmic and extracellular spaces (Anon and Calvelo, 1980).

The average values and the standard deviation of WBC were calculated for fresh and frozen samples (Fig. 9). The frozen samples had less water binding capacity than the fresh one though the difference was not significant. There is a general agreement in the scientific literature that water binding capacity of meat is gradually reduced due to freezing, frozen storage and thawing (Vieira et al., 2009). Research showed that the possible reason of decreasing water binding capacity is not only the disruption of muscle fiber structure but also the denaturation of proteins. It has been found that sarcoplasmic proteins are one of the main components of drip (Savage, Warris, and Jolley, 1990).

Fat content: Fat content for fresh and frozen samples were $5.08 \%$ and $6.09 \%$, respectively (Fig. 10) The fat content is very low for both fresh and frozen sample because the samples were free from subcutaneous and additional fat. The fat content of the frozen sample is a 
little bit higher because of the dry matter content. The moisture content decreased in the frozen sample,

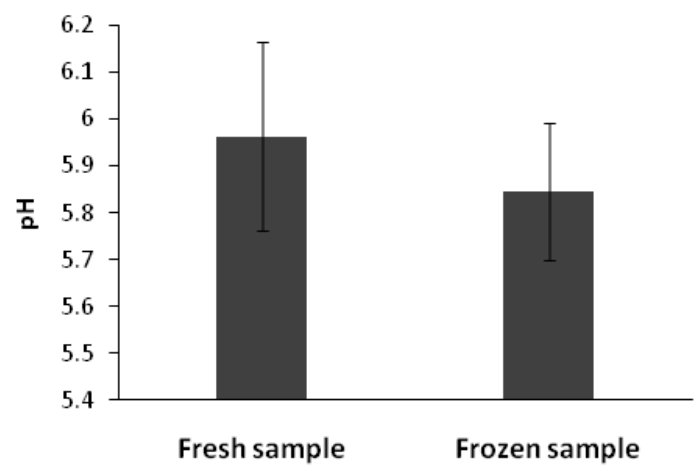

Fig. 1. $\mathrm{pH}$ values of fresh and frozen samples $(\mathrm{p}<0.05)$

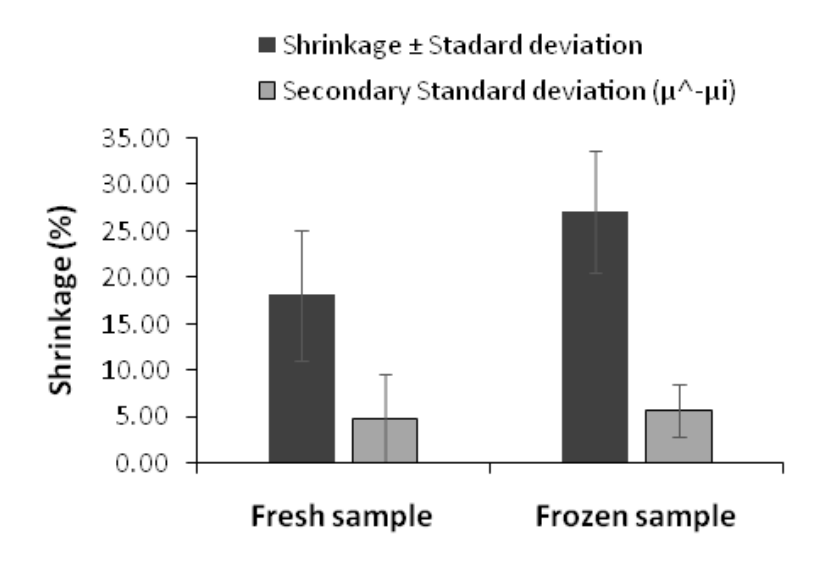

Fig. 3. Values of shrinkage (\%) and secondary standard deviation of fresh and frozen samples $(\mathrm{p}<0.05)$

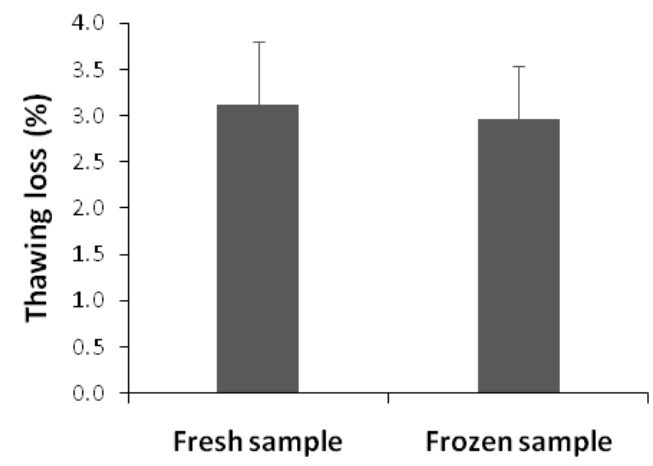

Fig. 5. Value of thawing loss (\%) of fresh and frozen samples $(\mathrm{p}<0.05)$ therefore, the dry matter content increased which result in higher fat content in the frozen sample.

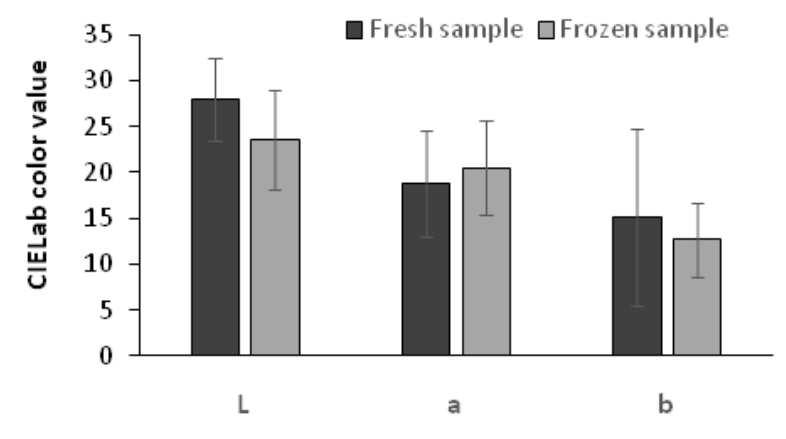

Fig. 2. Values of CIELab color measurement (L, a and $b$ values) of the fresh and frozen sample $(\mathrm{p}<0.05)$.

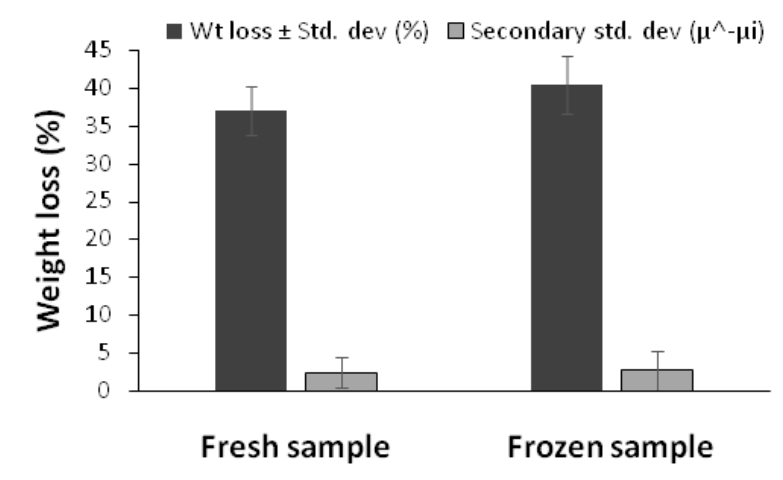

Fig. 4. Values of weight loss (\%) and secondary standard deviation of fresh and frozen samples $(\mathrm{p}<0.05)$

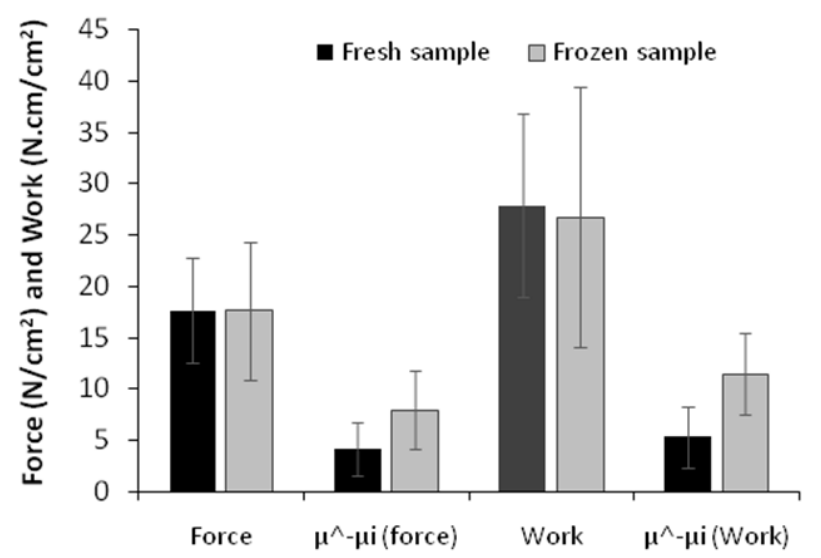

Fig. 6. Force and work of fresh and frozen samples with secondary standard deviation $(\mathrm{p}<0.05)$ 


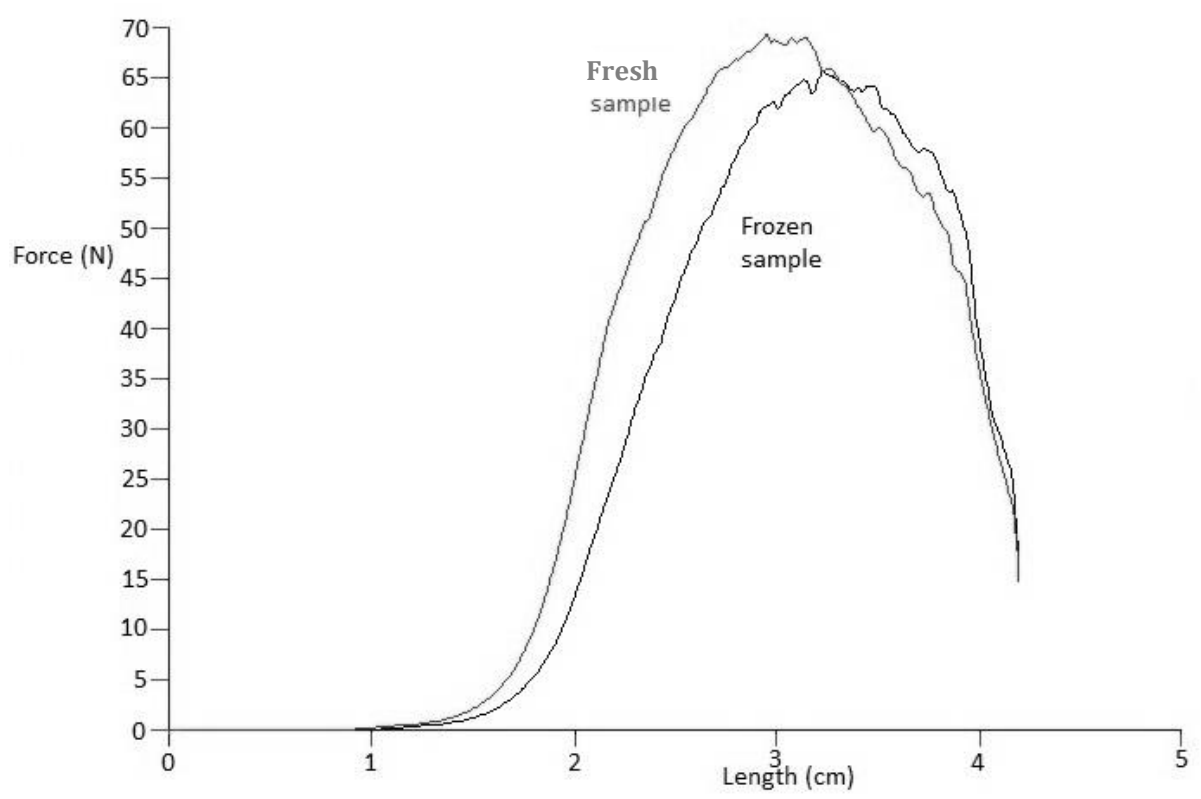

Fig. 7. Values of force between fresh and frozen lamb meat samples

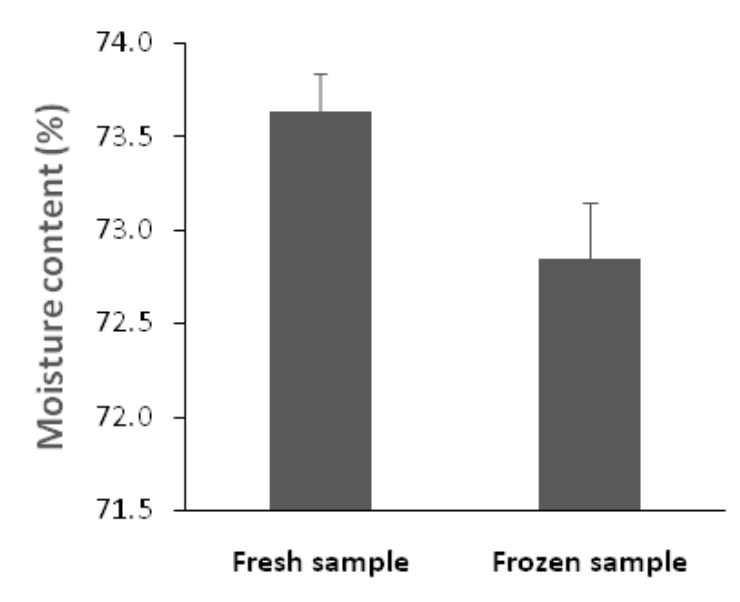

Fig. 8. Moisture content of fresh and frozen lamb meat samples $(\mathrm{p}<0.05)$

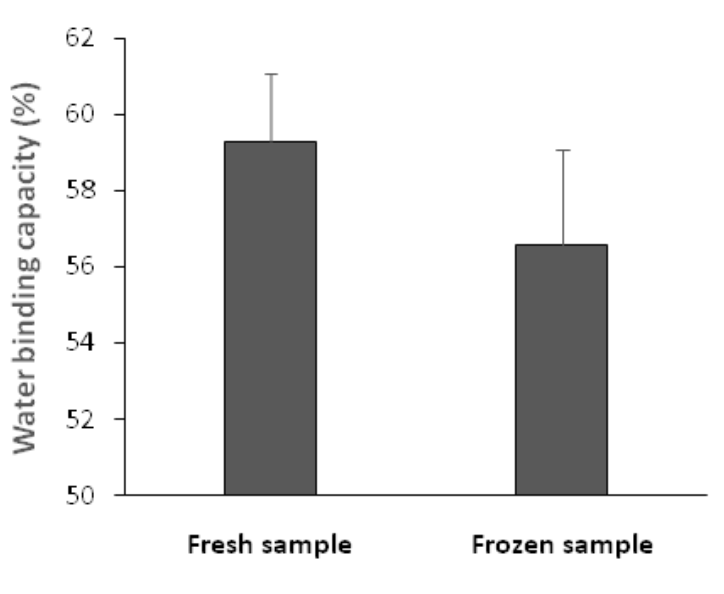

Fig. 9. Water binding capacity of fresh and frozen lamb meat samples $(\mathrm{p}<0.05)$ 


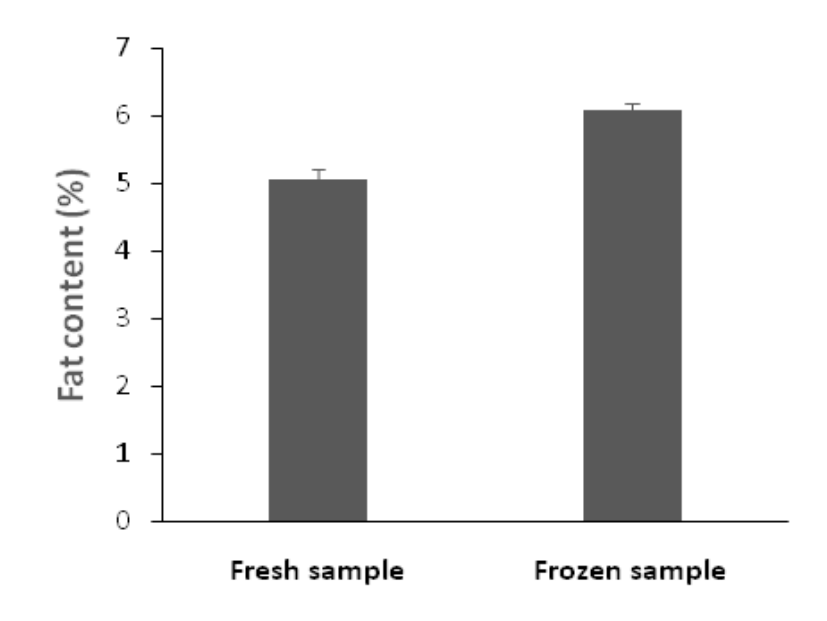

Fig. 10. Fat content of fresh and frozen lamb meat samples $(\mathrm{p}<0.05)$

\section{Recommendation and Conclusion}

None of the quality attributes showed any significant different except shrinkage and texture. Shrinkage analysis done only on length showed a significant difference. Shrinkage analysis should have been done on three-dimensionally i.e. length, width and height to get the more realistic value. The standard deviation of force and work showed very scattered data. So, the absolute values were calculated from the mean value and each value and this absolute value showed a significant difference for both force and work. For frozen sample, the freezing time, temperature and packaging materials are very important factors which affect the quality. Few months freezing time would give more differences. From this experiment, a realistic conclusion can be made if the sensory evaluation along with flavor analysis was done at the same time. From all the results of these quality attributes, it can be said that fresh and frozen lamb meat samples showed significant differences in case of shrinkage and texture analysis and very limited differences in case of $\mathrm{pH}$, color, moisture content, water binding capacity and fat.

\section{References}

Abdallah, M.B., Marchello, J.A., and Ahmad, H.A. 1999. Effect of freezing and microbial growth on myoglobin derivatives of beef. J. Agril. Food Chem., 47: 4093-4099.

Añón, M.C. and Cavelo, A. 1980. Freezing rate effects on the drip loss of frozen beef. J. Meat Sci., 4: 1-14.

CIELAB. 2014. A guide to understand color communication. Retrieved from www.x-rite.com.

Dickson-Hoyle, S. and Reenberg, A. 2009. The shrinking globe: Globalisation of food system and the changing geographies of livestock production. Danish J. Geography, 109, 105-112.

Earle, R.L. and Fleming, A.K. 1967. Cooling and freezing of lamb and mutton carcasses. Food Technol. 21(1): 79.

Fernandez-Lopez, J., Zhi, N., Aleson-Carbonell, L., Perez-Alvarez, J.A., and Kuri, V. 2005. Antioxidant and antibacterial activities of natural extracts: application in beef meatballs. J. Meat Sci., 69: 371-380.

Fleming, A.K. and Earle, R.L., 1968. Cooling and freezing of lamb and mutton carcasses. 2. Weight loss during cooling. Food Techno., 22(1): 100-112.

Gomez, K.A., and Gomez. A.A. 1984. Statistical Procedures for Agricultural Research. A Wiley Int. Sci. Pub. John Wiley and Sons, New York, Brisbane, Singapore. pp. 139-240.

Grau, R. and Hamm, R. 1953. Eine einfache Methode zur Bestimmung der Wasserbinding im Fleisch. Die Fleischwirtschaft, 4: 295-297.

Lawrie, R.A. 1998. Lawrie's meat science. 6th ed. Lancaster, PA: Technomic Publishing Inc.

Leygonie, C., Britz, T.J. and Hoffman, L.C. 2011. Oxidative stability of previously frozen ostrich M. iliofibularis packaged under different modified atmospheric conditions. International J. Food Sci. and Technol., 46: 1171-1178.

Leygonie, C., Britz, T.J. and Hoffman, L.C. 2012. Impact of freezing and thawing on the quality of meat: Review. J. Meat Sci., 91: 93-98.

Livingston, D.J., and Brown, W.D. 1981. The chemistry of myoglobin and its reactions. Food Technol., 35: 238-252.

Lagerstedt, Å., Enfält, L., Johansson, L., and Lundström, K. 2008. Effect of freezing on sensory quality, shear force and water loss in beef M. longissimus dorsi. Meat Sci., 80(2), 457461.

Lui, Z., Xiong, Y., and Chen, J. 2010. Protein oxidation enhances hydration but suppresses water-holding capacity in Porcine Longissimus muscle. J. Agril. Food Chem., 58: 1069710704.

Mahy, M., Eycken, L. and A. Oosterlinck, A. 1994. Evaluation of uniform color spaces developed after the adoption of CIELAB and CIELUV. Color Res. Appl., 19(2): 105-121.

Meat Update. 2014. Sheep meat eating quality. CSIRO meat technology update. Tingalpa, Qld.: Food Science Australia. Retrieved from www.meatupdate .csiro.au.

Met, A., Celik, A., Oncul, A. and Hocaoglu, S. 2013. Investigation of different thawing methods combined with freezing rate on slab shape meat quality. Proceedings of the $59^{\text {th }}$ International Congress of Meat Science and Technology, Cork, pp.18-23.

Newsome, R.L., Mody, W.G., Langlois, B.E., Gay, N., McMillan, M. and Fox, J.D. 1985. Effects of cattle-finishing systems on carcass traits and aging methods on loin shrinkage and steak color. J. Animal Sci., 60: 1208-1218.

Obuz, E., Dikeman, M.E., Grobbel, J.P., Stephens, J.W., and Loughin, T.M. 2004. Beef longissimus lumborum, biceps femoris, and deep pectoralis Warner-Bratzler shear force is affected differently by end point temperature, cooking method, and USDA quality grade. Meat Sci., 68: 243-248.

Palka, K., and Daun, H. 1999. Changes in texture, cooking losses, and miofibrillar structure of bovine M. semitendinosus during heating. Meat Sci., 51: 237-243.

Rahman, M.H., Hossain, M.M., Rahman, S.M.E., Hashem, M.A. and Oh, D.H. 2014. Effect of repeated freeze-thaw cycles on beef quality and safety. Korean J. Food Sci. Animal Resour., 34(4), 482.

Rahman, M.H., Hossain, M.M., Rahman, S.M.E., Amin, M.R., and Oh, D.H. 2015. Evaluation of physicochemical deterioration and lipid oxidation of beef muscle affected by freeze-thaw cycles. Korean J. food Sci. Animal Resour., $35(6), 772$.

Renerre, M. 1990. Factors involved in the discoloration of beef meat. Interl. J. Food Sci. Technol., 25: 613-630. 
Savage, A.W., Warris, P.D., and Jolley, P.D. 1990. The amount and composition of the proteins in drip from stored pig meat. Meat Sci., 27: 289-303.

Singh, R.P. and Wang, C.Y. 1977. Quality of frozen foods- a review. J. Food Process Engg., 1:97-128.

Spooncer, W.F., Smith, D.R. and Powell, V.H. 1979. The effect of chilling and freezing on meat quality. Refrigeration for Meat Industry Engineers and consultants. Retrieved from www.meatupdate.csiro.au/data/Refrigeration_02-79.pdf Accessed on [5 October, 2014].
Tornberg, E. 2005. Effects of heat on meat proteins -implications on structure and quality of meat products. Meat Sci., 70: 493-508.

Vieira, C., Diaz, M.Y., Martínez, B., and García-Cachán, M.D. 2009. Effect of frozen storage conditions (temperature and length of storage) on microbial and sensory quality of rustic crossbred beef at different stages of aging. Meat Sci., 83: 398-404. 